\title{
SOLUBILITY ENHANCEMENT OF POORLY WATER SOLUBLE DRUGS
}

\author{
Tushar Gohil
}

Shree Leuva Patel Trust Pharmacy Mahila College University Saurashtra, Gujarat, 388001, India.

Submitted: 19-09-2013

Revised: 29-10-2013

Accepted: 06-12-2013

*Corresponding author Tushar Gohil

Email :

gtushar_13@yahoo.co.in

\begin{abstract}
Aqueous solubility is a limiting factor in the oral bioavailability of a certain class of poorly water soluble drugs. A consequence of low aqueous solubility is a slow dissolution rate. For the drugs with low aqueous solubility and high permeability the dissolution rate will be the rate limiting step for absorption. The most successful techniques that are employed for dissolution enhancement are micronization, formulation of amorphous systems and cyclodextrins containing dosage forms. This combined approaches to improve the dissolution of some poorly soluble drugs. Micronization increases the dissolution rate of drugs through increased surface area. The high surface area of drug micro/nano particles renders them thermodynamically unstable, promoting agglomeration and crystal growth. Microparticles of the poorly water soluble drugs were produced by the supercritical antisolvent method and simultaneously mixed with pharmaceutical excipients in a single step to prevent the drug agglomeration of drug particles. In the third approach cyclodextrins (CDs) were used as pharmaceutical solubilizers and inclusion complexes of drugs with $\beta-C D$.
\end{abstract}

Key words: micronization, supercritical antisolvent, cyclodextrins

\section{INTRODUCTION}

Poor aqueous solubility of drugs is an industry wide issue for pharmaceutical scientists. Because of their low aqueous solubility, up to $40 \%$ of new chemical entities fail to reach market despite exhibiting potential pharmacodynamic activities (Lipinski 2005). In addition, up to $50 \%$ of orally administered drugs suffer from formulation problems related to their high lipophilicity (Gursoy and Benita 2004). Poorly aqueous soluble drugs are associated with slow drug absorption leading eventually to inadequate and variable bioavailability (Amidon et al., 1995; Leuner and Dressman, 2000). Oral absorption of a drug can be influenced by variety of factors, such as the physicochemical properties (e.g., pKa, solubility, stability, diffusivity, lipophilicity, polar-nonpolar surface area, presence of hydrogen bond functionalities, particle size and crystal form), physiological conditions (e.g., gastrointestinal $\mathrm{pH}$, blood flow, gastric emptying, small intestinal transit time, colonic transit time and absorption mechanisms) and type of dosage form (e.g., tablet, capsule, solution, suspension and emulsion). Despite this complexity, the work revealed that permeability of drug through the gastrointestinal (GI) membrane and solubility/ dissolution of drug dose in the GI environment are the fundamental events in successful drug absorption (Dahan et al., 2009). The Biopharmaceutics Classification System (BCS) classifies drugs into four categories (Table I) based on their solubility and permeability characteristics. According to BCS, the oral bioavailability of class-II (poorly soluble and highly permeable) drugs is limited by their solubility and dissolution rate (Yu et al., 2002).

Table I. Biopharmaceutics classification system

\begin{tabular}{ll}
\hline Class-I & Class-II \\
High Solubility, & Low Solubility, \\
High Permeability & High Permeability \\
\hline Class-III & Class-IV \\
High Solubility, & Low Solubility, \\
Low Permeability & Low Permeability \\
\hline
\end{tabular}

If the ratio of the drug dose to the lowest drug saturation solubility in the $\mathrm{pH}$ range of $1-8$ is greater than 250 then the drug is 
called poorly soluble. So regardless of other factors, it is reasonable to conclude that a compound must be in solution form or solubilized in the GI tract to diffuse into and across the enterocytes lining the intestinal lumen for absorption (Gullapalli, 2001). The complete oral absorption of a drug depends on the events depicted in Equation 1, their importance relative to one another and the rate at which they occur (Dressman and Reppas, 2000). Drug release (dissolution) and absorption must occur within the available transit time i.e., the time the drug spends in GI tract and at the site of absorption. The dissolution rate of the drug is given by the Noyes-Whitney equation.

Dissolution rate $=\frac{d X}{d t}=\frac{A \cdot D}{h}\left[\frac{C s-X d]}{V}\right]$

Where $A$ is the surface area of the drug; $D$ is the diffusion coefficient of the drug; $b$ is the effective boundary layer thickness; $C s$ is the saturation concentration of the drug under the local GI conditions; $V$ is the volume of the fluid available to dissolve the drug, and $X d$ is the amount of drug already dissolved.

The diffusion coefficient (D) and diffusion layer thickness (h) are less suitable targets for dissolution rate enhancement/ bioavailability optimization. $D$ depends on the molecular weight of the drug and the viscosity of the gastro intestinal fluids, which varies in the fed and fasted state and is subject to large intra- and inter-subject variability. $b$ also largely depends on the hydrodynamics during GI transit. Therefore, based on the equation 1, the possibilities for increasing the dissolution/ bioavailability are to increase the effective surface area or to improve the apparent solubility of the drug. Different approaches to enhance the dissolution rate of poorly soluble drugs include, but are not limited to, particle size reduction (Rasenack and Mueller, 2002; Jounela et al., 1985; Liversidge and Cundy, 1995; Vogt et al., 2008), inclusion complexation with cyclodextrins (Brewster, et al., 1992; BadrEldin, et al., 2008; Sathigari et al., 2009),solid dispersion (Joshi et al., 2004; Dannenfelser, et al., 2004; Kennedy et al., 2008), salt formation (Han, et al., 2007; O'Connor and Corrigan, 2001), use of surfactants (Balakrishnan et al., 2004; Chiou, et al., 1976), cosolvency
(Kawakami et al., 2004; Viernstein et al., 2003), and various particle engineering techniques (Blagden, et al., 2007; Jung and Perrut, 2001; Loth and Hemgesberg, 1986). Among, the different approaches, they are the most successful technologies in terms of the number of commercial products which are on the market (Tables II, III and IV).

\section{Micro/Nano particle production}

This is one of the most efficient and reliable methods used commercially to improve the bioavailability of poorly soluble drugs that is limited by poor dissolution rates (Jonghwi, 2003). Improvement in bioavailability after micronization of drugs has been well documented for numerous drugs (Farinha, et al., 2000). Micronization increases the dissolution rate of drugs through increased surface area (Barrett, et al., 2008). Reduction of the particle size to micron or nano size can be achieved by precipitation from a solution (builtup) or milling (sized-down). Milling is a well established technique which is relatively cheap, fast and is easy to scale-up, but it has several disadvantages (Wong, et al., 2006). This method has limited opportunity to control the final particle size, shape, morphology, surface properties and electrostatic charge and it is difficult to reduce the particle size below $1 \mu \mathrm{m}$ because of the cohesiveness of the particles. In addition, milling is a high energy process which causes disruptions in the drugs crystal lattice, resulting in the presence of disordered or amorphous regions in the final product (Saleki-Gerhardt, et al., 1996). Wet milling techniques (bead milling and high pressure homogenization) can produce submicron particles without any concern for particle cohesiveness. However, these techniques often require a long time, introduce impurities, can also cause disruptions in the drug crystal lattice, and limits flexibility in controlling particle morphology. These methods also require further pharmaceutical operations such as lyophilization or spray drying to produce solids for use in oral solid dosage forms. Supercritical fluids are involved in numerous industrial processes and offer considerable advantages as solvents or anti solvents for crystallization and precipitation processes (Matteucci, 2006). 
Table II. List of nano/ micro particle based drugs that are commercialized

\begin{tabular}{lllll}
\hline Description & Drug & Technology & Brand name & Company \\
\hline Downsizing & Aprepitant & NanoCrystal (Elan) & Emend ${ }^{\circledR}$ & Merck \\
& Sirolimus & $\begin{array}{l}\text { NanoCrystal } \\
\text { (Elan) }\end{array}$ & Rapamune ${ }^{\circledR}$ & Pfizer \\
& Fenofibrate & $\begin{array}{l}\text { Nanocrystal } \\
\text { (Elan) }\end{array}$ & Tricor ${ }^{\circledR}$ & Abbott \\
& Paliperidone & Nanocrystal & Invege & Janseen \\
& Palmitate & (Elan) & Sustenna ${ }^{\circledR}$ & Par \\
& $\begin{array}{l}\text { Megestrol } \\
\text { Acetate }\end{array}$ & Nanocrystal & Megace ES ${ }^{\circledR}$ & Pharmaceuticals \\
& Flan) & Triglide ${ }^{\circledR}$ & Skyepharma \\
\hline
\end{tabular}

Table III. Commercially available solid dispersion

\begin{tabular}{lll}
\hline Drug & Brand name & Company \\
\hline Griseofulvin & Gris-PEG ${ }^{\circledR}$ & Pedinol Pharmcal Inc. \\
Nabilone & Cesamet ${ }^{\circledR}$ & Valent Pharmaceutical \\
Lopinavir,Ritonavir & Kaletra ${ }^{\circledR}$ & Abbot \\
Itraconazole & Sporanox ${ }^{\circledR}$ & Janseen pharmaceutical \\
Etravirin & Intelence ${ }^{\circledR}$ & Tibotec \\
Everolimus & Certican ${ }^{\circledR}$ & Novartis \\
Verapamil & Isoptin SR-E® & Abbott \\
Nivaldipine & Nivadil ${ }^{\circledR}$ & Fujisawa Pharmaceutical Co.Ltd. \\
Tacrolimus & Prograf & Fujisawa Pharmaceutical Co.Ltd. \\
Troglitazone & Rezulin ${ }^{\circledR}$ & Developed by Sankyo,manufactured by Parke-Davis \\
\hline
\end{tabular}

Among different methods using supercritical fluids, precipitation using supercritical carbon dioxide $\left(\mathrm{CO}_{2}\right)$ as an antisolvent is well known and has been used to micronize several kinds of compounds (Jung and Perrut, 2001). Carbon dioxide is an ideal supercritical fluid because of its low critical temperature $\left(31.18^{\circ} \mathrm{C}\right)$ and pressure $(73.8 \mathrm{~Pa})$, low cost, non-toxicity and inert nature. In addition, $\mathrm{CO}_{2}$ is recyclable and environmentally safe (Rogers, et al., 2004). The driving force for particle formation using supercritical fluids is super saturation which is same as that of traditional crystallization. In the supercritical anti-solvent process the solubilization power of a solvent is decreased by addition of a supercritical fluid as an antisolvent in which the solute is insoluble (Figure 1). The nucleation and consequent growth of the crystals from the solute-organic solventantisolvent are governed by the diffusion of the antisolvent into the organic phase and the evaporation of the organic solvent into the antisolvent phase (Reverchon and Della 2001). The rapid diffusion of antisolvent into the organic solvent produces the supersaturation of the solute that leads to nucleation and particle formation.

\section{Complexation with Cyclodextrins}

Cyclodextrins (CDs) have been used extensively in pharmaceutical research and development, and there are currently over 30 marketed cyclodextrins containing pharmaceutical products world wide (Pasquali, et al., 2008). Some of the cyclodextrins based marketed products world wide are given in Table IV (Lengsfeld, et al., 2000). Most commonly, CDs are used in drug formulations as solubility enhancers because of their ability to form water soluble inclusion complexes with poorly soluble drugs. The complexation with 
Table IV. List of marketed pharmaceutical containing cyclodextrins

\begin{tabular}{|c|c|c|c|}
\hline Drug & Brand name & Company & Formulation \\
\hline \multicolumn{4}{|l|}{$\alpha$ cyclodextrin $(\alpha \mathrm{CD})$} \\
\hline Cefotiam-hexetil HCL & Pansporin & Takeda & Tablet \\
\hline OP-1206 & Opalmon & Ono & Tablet \\
\hline \multicolumn{4}{|l|}{$\beta C y c l o d e x t r i n(\beta C D)$} \\
\hline \multirow[t]{2}{*}{ Benexate $\mathrm{Hcl}$} & Ulget & Teikoku & Capsule \\
\hline & Lonmiel & Shionogi & Capsule \\
\hline Cephalosporin & Meiact & Meiji Seika & Tablet \\
\hline Nicotine & Nicorette & Pfizer & Tablet \\
\hline Nimesulide & Nimedex & Novartis & Tablet \\
\hline \multicolumn{4}{|l|}{$\begin{array}{l}\text { 2-Hydroxy propyl- } \beta \text { - } \\
\text { cyclodextrin(HP } \beta C D)\end{array}$} \\
\hline Itraconazole & Sporanox & Janssen & Oral and IV solution \\
\hline \multicolumn{4}{|l|}{$\begin{array}{l}\text { Sulfabutyl ether- } \beta \text {-cyclodextrin } \\
\text { sodium salt }\end{array}$} \\
\hline Voriconazole & Vfend & Pfizer & IV solution \\
\hline Ziprasidone Mesylate & Geodon Zeldox & Pfizer & IM solution \\
\hline Aripiprazole & Abilify & BMS & IM solution \\
\hline
\end{tabular}

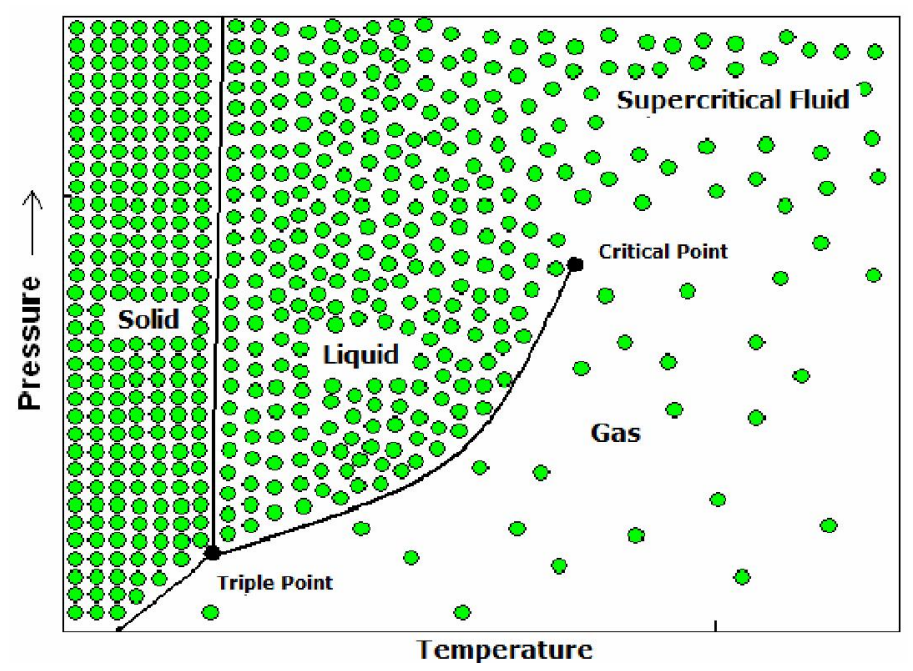

Figure 1 Phase diagram showing supercritical fluid region.

CDs enhances the solubility, dissolution rate, and bioavailability of poorly soluble drugs. In addition, $\mathrm{CDs}$ are used to enhance stability, to mask drug taste, to aid pharmaceutical processes by serving as filler, binder and channeling agents, etc., and as an osmogen in controlled release osmotic pump dosage forms. CDs are cyclic $(\alpha-1,4)$-linked oligosaccharides of $\alpha$-D-glucopyranose containing a relatively hydrophobic central cavity and hydrophilic outer surface. The central cavity provides a lipophillic microenvironment into which suitably sized lipophilic drug molecules can be accommodated due to hydrophobic interactions. No covalent bonds are formed in the drug/cyclodextrin (CD) complexation and the complexes are readily dissociated. The three natural CDs are $\alpha-C D, \beta-C D$, and $\gamma$ CD which are made up of 6,7 or 8 glucopyranose units respectively. Several chemically modified CD derivatives have been reported in the literature to enhance the 
aqueous solubility, physical and microbiological stability and to reduce toxicity of the parent CDs. The majority of drugs form apparent 1:1 complexes with CDs although the formation of higher order complexes is not uncommon (Gupta, 2007).

\section{Amorphous system}

Amorphization is one of the techniques to enhance the dissolution rate and bioavailability of poorly water soluble drugs (Pasquali and Bettini, 2008). Delivering the pharmaceutical active ingredient in the amorphous form is very attractive due to the potentially large increases in drug solubility, dissolution rate, and bioavailability (Baldyga, 2010). The amorphous form of drugs can have as much as a 10-1600 fold higher solubility than their crystalline forms (Yasuji, 2008). The improvement in dissolution of amorphous systems can be attributed to improved wetting of the drug, deagglomeration and micellization of the drug with hydrophilic polymers and the high energy amorphous state of the drug (Ito, 2006).

However, the amorphous forms of drugs are physically unstable due to their higher energy state and may recrystallize over pharmaceutically relevant time scales, negating any solubility advantage. The most typically used approach to stabilize an amorphous system is to combine it with pharmaceutically acceptable polymers, such as polyvinylprrolidone, polyvinylpyrrolidone vinyl acetate, polyethylene glycol and various hydroxypropylmethyl cellulose and polyacrylic acid derivatives (Hancock, 1997). Thermodynamically the drug has a lower chemical potential when mixed with a polymer, resulting in a change of crystallization driving force ( $\mathrm{Yu}, 2001)$. The long polymeric chains can sterically hinder the association between drug molecules and, thereby, inhibit the recrystallization of drug. In addition, the interaction between the drug and polymer provides an increased energy barrier for nucleation and, consequently, enhances the physical stability (Hancock and Parks 2000). Amorphous drug-polymer systems are commonly characterized in terms of physical properties such as the glass transition temperature $(T g)$, heat capacity and miscibility.
Although it is still not completely clear as to how the polymer stabilizes.

The amorphous drug in the mixture, drug polymer miscibility is generally considered as one of the critical attributes that affect the stability of the amorphous systems, which in turn is dictated by the thermodynamics of mixing (Chokshi et al., 2007). The entropy of mixing is always favorable (an increase on mixing) providing one driving force facilitating mixing. The enthalpic component of the Gibbs function of mixing is controlled by the relative strength of the cohesive drug - drug, polymer polymer and the drug - intercomponent interactions (Konno and Taylor 2006).

\section{CONCLUSION}

Microparticles of the poorly water soluble drugs were produced by the supercritical antisolvent method and simultaneously mixed with pharmaceutical excipients in a single step to prevent the drug agglomeration of drug particles. In the third approach cyclodextrins (CDs) were used as pharmaceutical solubilizers and inclusion complexes of drugs with $\beta$-CD

\section{ACKNOWLEDGMENT}

We are thankful to the Shree Leuva Patel Trust Pharmacy Mahila College University Saurashtra, Mumbai for providing the support for this research work

\section{REFERENCES}

Amidon GL., Lennernas H., Shah VP., Crison JR. 1995; A theoretical basis for a biopharmaceutic drug classification: the correlation of in vitro drug product dissolution and in vivo bioavailability. Pharm Res. 12(3):413-420.

Badr-Eldin SM., Elkheshen SA., Ghorab MM. 2008; Inclusion complexes of tadalafil with natural and chemically modified beta-cyclodextrins. I: Preparation and invitro evaluation. Eur J Pharm Biopharm. 70(3):819-827.

Balakrishnan A., Rege BD., Amidon GL., Polli JE.2004;Surfactant-mediated dissolution: Contributions of solubility enhancement and relatively low micelle diffusivity. $J$ Pharm Sci. 93(8):2064-2075. 
Baldyga J., Czarnocki R., Shekunov BY., Smith KB. 2010; Particle Formation in Supercritical Fluids - Scale-up Problem. Chem Eng Res Des. 88:331-341.

Barrett AM., Dehghani F., Foster NR. 2008; Increasing the Dissolution Rate of Itraconazole Processed by Gas Antisolvent Techniques using Polyethylene Glycol as a Carrier. Pharm Res. 25(6):1274-1289.

Blagden N., de Matas M., Gavan PT., York P. 2007; Crystal engineering of active pharmaceutical ingredients to improve solubility and dissolution rates. Adv Drug Deliv Rev. 59(7):617-630.

Brewster ME., Loftsson T., Estes KS., Lin JL., Fridriksdottir H., Bodor N. 1992; Effect of various cyclodextrins on solution stability and dissolution rate of doxorubicin hydrochloride. Int I Pharm. 79(2-3):289-299.

Chiou WL., Chen SJ., Athanikar N. 1976; Enhancement of dissolution rates of poorly water-soluble drugs by crystallization in aqueous surfactant solutions. I: sulfathiazole, prednisone, and chloramphenicol. I Pharm Sci. 65(11):1702-1704.

Chokshi RJ., Zia H., Sandhu HK., Shah NH., Malick WA. 2007; Improving the dissolution rate of poorly water soluble drug by solid dispersion and solid solution: pros and cons. Drug Deliv. 14(1):33-45.

Dahan A., Miller JM., Amidon GL. 2009; Prediction of solubility and permeability class membership: provisional BCS classification of the world's top oral drugs. AAPS J. 11(4):740-746.

Dannenfelser RM., He H., Joshi Y., Bateman S., Serajuddin ATM. 2004; Development of clinical dosage forms for a poorly water soluble drug I: application of polyethylene glycol-polysorbate 80 solid dispersion carrier system. J Pharm Sci. 93(5):1165-1175.

Dressman JB., Reppas C. 2000; In vitro-in vivo correlations for lipophilic, poorly watersoluble drugs. Eur J Pharm Sci 11 Suppl. 2:S73-80
Farinha A, Bica A, Tavares P. 2000; Improved bioavailability of a micronized megestrol acetate tablet formulation in humans. Drug Dev Ind Pharm. 26(5):567-570.

Gullapalli RP. Soft gelatin capsules (softgels). J Pharm Sci 2001; 99(10):4107-4148.

Gupta RB., Shim JJ. 2007; Solubility in Supercritical Carbon Dioxide. New York; Taylor and Francis Group.

Gursoy RN., Benita S. 2004; Self-emulsifying drug delivery systems (SEDDS) for improved oral delivery of lipophilic drugs. Biomed Pharmacother. 58(3):173-182.

Han HK., Choi HK. 2007; Improved absorption of meloxicam via salt formation with ethanolamines. Eur J Pharm Biopharm. 65(1):99-103.

Hancock BC., Parks M. 2000; What is the true solubility advantage for amorphous pharmaceuticals? Pharm Res. 17(4):397404.

Hancock BC., Zografi G. 1997; Characteristics and significance of the amorphous state in pharmaceutical systems. J Pharm Sci. 86(1):1-12.

Ito A., Watanabe T., Yada S., Hamaura T., Nakagami H. et al., 2006; Prediction of recrystallization behavior of troglitazone /polyvinylpyrrolidone solid dispersion by solid-state NMR. Int J Pharm. 383(12):18-23.

Jonghwi L. 2003; Drug nano and microparticles processed into solid dosage forms: physical properties. J Pharm Sci. 92(10):2057-2068.

Joshi HN., Tejwani RW., Davidovich M., Sahasrabudhe VP., Jemal M., et al. 2004; Bioavailability enhancement of a poorly water-soluble drug by solid dispersion in polyethylene glycol-polysorbate 80 mixture. Int J Pharm. 269(1):251-258.

Jounela AJ., Pentikainen PJ., Sothmann A. 1985; Effect of particle size on the bioavailability of digoxin. Eur J Clin Pharmaco. 8(5):365-370.

Jung J., Perrut M. 2001;Particle design using supercritical fluids: Literature and patent survey. J Supercrit Fluids. 20(3):179-219.

Kawakami K, Miyoshi K, Ida Y. Solubilization behavior of poorly soluble drugs with combined use of Gelucire 44/14 and 
cosolvent. J Pharm Sci. 2004; 93(6):14711479.

Kennedy M, Hu J., Gao P., Li L., Ali-Reynolds A. et al., 2008; Bioavailability of a Poorly Soluble VR1 Antagonist Using an Amorphous Solid Dispersion Approach: A Case Study. Mol Pharm. (6):981-993.

Konno H., Taylor LS. 2006; Influence of different polymers on the crystallization tendency of molecularly dispersed amorphous felodipine. J Pharm Sci. 95(12):2692-2705

Lengsfeld CS, Delplanque JP, Barocas VH, Randolph TW. 2000; Mechanism Governing Microparticle Morphology during Precipitation by a Compressed Antisolvent: Atomization vs Nucleation and Growth. $J$ Phys Chem B. 104(12):2725-2735.

Leuner C, Dressman J. 2000; Improving drug solubility for oral delivery using solid dispersions. Eur J Pharm Biopharm. 50(1):47-60.

Lipinski CA. 2005; Poor aqueous solubility- An industry wide problem in drug discovery. Am Pharm Rev 5(3):82-85.

Liversidge GG., Cundy KC. 1995; Particle size reduction for improvement of oral bioavailability of hydrophobic drugs: I. Absolute oral bioavailability of nanocrystalline danazol in beagle dogs. Int J Pharm. 125(1):91-97.

Loth H., Hemgesberg E. 1986; Properties and dissolution of drugs micronized by crystallization from supercritical gases. Int J Pharm. 32(2-3):265-267.

Matteucci ME., Hotze MA., Johnston KP., Williams RO., 2006; 3rd. Drug nanoparticles by antisolvent precipitation: mixing energy versus surfactant stabilization. Langmuir. 22(21):8951-8959.

Noyes AA., Whitney WR. 1997; The rate of solution of solid substances in their own solutions. J Am Chem Soc. 19:930-934.

O'Connor KM, Corrigan OI. Comparison of the physicochemical properties of the $\mathrm{N}$ (2-hydroxyethyl)pyrrolidine, diethylamine and sodium salt forms of diclofenac. Int J Pharm. 2001; 222(2):281293.
Pasquali I., Bettini R., Giordano F. 2006; Solidstate chemistry and particle engineering with supercritical fluids in pharmaceutics. Eur J Pharm Sci. 27(4):299-310.

Pasquali I, Bettini R, Giordano F. Supercritical fluid technologies: An innovative approach for manipulating the solid-state of pharmaceuticals. Adv Drug Deliv Rev. 2008; 60(3):399-410.

Pasquali I, Bettini R. 2008; Are pharmaceutics really going supercritical? Int J Pharm. 364(2):176-187.

Rasenack N, Mueller BW. 2002; Dissolution Rate Enhancement by in Situ Micronization of Poorly Water-Soluble Drugs. Pharm Res. 19(12):1894-1900.

Reverchon E, Della PG. 2001; Supercritical fluids-assisted micronization techniques: Low-impact routes for particle production. Pure Appl Chem. 73(8):12931297.

Rogers TL., Gillespie IB., Hitt JE., Fransen KL., Crowl CA. et al. 2004; Development and Characterization of a Scalable Controlled Precipitation Process to Enhance the Dissolution of Poorly Water-Soluble Drugs. Pharm Research. 21(11):2048-2057.

Saleki-Gerhardt A, Ahlneck C, Zografi G. 1996; Assessment of disorder in crystalline solids. Int J Pharm. 101(3):237247.

Sathigari S., Chadha G., Phillip LYH., Wright N, Parsons DL. et al., 2009; Physicochemical characterization of efavirenzcyclodextrin inclusion complexes. AAPS PharmSciTech. 10(1):81-87.

Viernstein H, Weiss-Greiler P, Wolschann P. 2003; Solubility enhancement of low soluble biologically active compoundstemperature and cosolvent dependent inclusion complexation. Int $J$ Pharm. 256(1-2):85-94.

Vogt M, Kunath K, Dressman JB. 2008; Dissolution enhancement of fenofibrate by micronization, cogrinding and spraydrying: Comparison with commercial preparations. Eur J Pharm Biopharm. 68(2):283-288.

Wong SM, Kellaway IW, Murdan S. 2006; Enhancement of the dissolution rate and 
oral absorption of a poorly water soluble drug by formation of surfactantcontaining microparticles. Int $\mathrm{J}$ Pharm. 317(1):61-68.

Yasuji T, Takeuchi H, Kawashima Y. 2008; Particle design of poorly water-soluble drug substances using supercritical fluid technologies. Adv Drug Deliv Rev. 60(3):388-398.
Yu L. 2001; Amorphous pharmaceutical solids: preparation, characterization and stabilization. Adv Drug Deliv Rev. 48(1):27-42.

Yu LX., Amidon GL., Polli JE., Zhao H., Mehta MU. et al., 2002; Biopharmaceutics classification system: the scientific basis for biowaiver extensions. Pharm Res. 19(7):921-925. 